\title{
CAR T-cell therapy and critical care
}

\section{A survival guide for medical emergency teams}

\author{
Anna S. Messmer (ID · Yok-Ai Que · Christoph Schankin · Yara Banz · Ulrike Bacher · Urban Novak · Thomas Pabst
}

Received: 3 May 2021 / Accepted: 1 September 2021 / Published online: 6 October 2021

(C) The Author(s) 2021

\begin{abstract}
Summary Chimeric antigen receptor (CAR) T-cells are genetically engineered to give $\mathrm{T}$-cells the ability to attack specific cancer cells, and to improve outcome of patients with refractory/relapsed aggressive B-cell malignancies. To date, several CAR T-cell products are approved and additional products with similar indication or extended to other malignancies are currently being evaluated. Side effects of CAR T-cell treatment are potentially severe or even life-threatening immune-related toxicities, specifically cytokine release syndrome (CRS) and immune effector cellassociated neurotoxicity syndrome (ICANS). Consequently, medical emergency teams (MET) are increasingly involved in the assessment and management of CAR T-cell recipients. This article describes the principles of CAR T-cell therapy and summarizes the main complications and subsequent therapeutic interven-
\end{abstract}

\section{Availability of data: Not applicable.}

A. S. Messmer, MD ( $\varangle) \cdot$ Y.-A. Que

Department of Intensive Care Medicine, Inselspital,

Bern University Hospital, University of Bern,

Freiburgstrasse 10, 3010 Bern, Switzerland

anna.messmer@insel.ch

U. Novak · T. Pabst

Department of Medical Oncology, Inselspital, Bern

University Hospital, University of Bern, Bern, Switzerland

C. Schankin

Department of Neurology, Inselspital, Bern University

Hospital, University of Bern, Bern, Switzerland

\section{Y. Banz}

Institute of Pathology, University of Bern, Bern, Switzerland

\section{U. Bacher}

Department of Haematology and Central Haematology Laboratory, Inselspital, Bern University Hospital, University of Bern, Bern, Switzerland tions aiming to provide a survival guide for METs with a proposed management algorithm.

Keywords Lymphoma - Chimeric antigen receptor T-cells $\cdot$ Cytokine release syndrome $\cdot$ Immune effector cell associated neurotoxicity $\cdot$ Medical emergency team

\section{Background}

The armamentarium of cancer therapies has rapidly evolved within the past two decades. Among recent approaches, targeting the patient's immunologic selfdefence and enhancing T-cell responses represent very promising developments. Checkpoint inhibitors, chimeric antigen receptor (CAR) T-cells, and bispecific antibodies attack cancer cells by activating immune effectors and/or decreasing their immune tolerance making them more vulnerable to the effects of immune system cells [1].

To date, several CAR T-cell products, e.g. tisagenlecleucel $\left(\mathrm{Kymriah}^{\circledR}\right)$, axicabtagene ciloleucel (Yescarta ${ }^{\circledR}$ ), brexucabtagene autoleucel (Tecartus ${ }^{\circledR}$ ), and lisocabtagene maraleucel (Breyanzi ${ }^{\circledR}$ ) are on the market, although some of them not yet approved by the European Medicines Agency (EMA). Most of them are targeting the CD19 antigen, expressed by most B-cell malignancies [2-6]. In patients with relapsed or refractory $(r / r)$ large B-cell lymphoma and patients with mantle cell lymphoma, CAR T-cell therapies have been shown to induce a temporary or even durable complete remission in the majority of patients $[4,5,7]$. In patients with relapsed B-ALL following allogeneic hematopoietic stem cell transplantation, CAR-T cell therapy provides the only curative approach [6]. In March this year, the first CAR-T cell product against multiple myeloma (idecabtagene vicleucel) has been approved, targeting the 
B cell maturation antigen (BCMA) [8]. In the coming months and years, approvals for additional CAR-T cell products for these indications and other B-cell malignancies are expected.

After CAR-T cell administration, patients can develop specific acute toxicities, namely cytokine release syndrome (CRS) [9-12] or immune effector cell-associated neurotoxicity syndrome (ICANS) [10, 12], that can vary from minor transient symptoms up to lifethreatening conditions. Therefore, early recognition by the oncologic team with timely involvement of critical care teams, i.e. medical emergency teams (MET), is crucial. This review article is a survival guide for METs with a summary of the key toxicities associated with CAR-T cell therapy and a proposal for a management algorithm.

\section{Principles of CAR T-cell therapy}

Autologous CAR-T cells are "living drugs" and are tailor-made for each individual patient. Therefore, a variety of logistic challenges and a complex production process precede CAR-T cell treatment [13]. In many instances, bridging strategies including cytotoxic compounds, B-cell antibodies, or radiotherapy, are needed to control the B-cell malignancy before the patient enters CAR-T cell therapy. Prior to CAR-T cell infusion, patients receive lymphocyte-depleting chemotherapy, to ensure tolerance and persistence of the administered CAR-T product [2]. In the weeks (and sometimes months) following CAR-T cell infusion, both CD19 and BCMA directed CAR-T cells show a wide range of interindividual expansion and proliferation dynamics in the recipient and subsequently exert their effects towards the malignant B-cell tissues as well as the healthy B-cell compartment.

\section{Key toxicities related to CAR T-therapy}

The American Society for Transplantation and Cellular Therapy (ASTCT) developed a recommendation for definition and grading for CAR T-related toxicity (Table $1 ;$ [10]). The grading systems are incorporated and easy to calculate on the CARTOX app, which has been developed by the MD Anderson Cancer Center in the USA [14]. The incidence and severity of CAR T-related toxicities are likely associated with high disease burden, a higher peak of CAR-T cell expansion in the peripheral blood, and high baseline inflammatory activity [11, 15-18]. Side effects of CAR-T cell therapy seems to be more pronounced in patients with ALL as compared to DLBCL $[4,6]$. Studies in patients treated for ALL reported a significant correlation between neurotoxicity and the presence of CRS as well as its severity [18]. In addition, the different CAR-T cell products have different rates of toxicities: Axicabtagene ciloleucel causes higher rates of ICANS than tisagenlecleucel $[3,4,19]$.

\section{Cytokine release syndrome (CRS)}

The CRS is the most common acute toxicity following CAR-T cell therapy with a reported incidence between $37 \%$ and $93 \%$ across different studies. [3, 4, 6, 20, 21]. The onset of CRS typically occurs within hours up to 4-7 days after CAR-T cell infusion, but late occurrence up to 14 days has also been reported [3, 4, 6, 20, 22].

The CRS is characterized by excessive immune reaction triggered by various factors, such as infections and immune-modulating drugs, in particular T-cell engaging treatment strategies [17, 23].

Increased IL-6 levels correlate with the onset of severe CRS symptoms [24] and seem to play a key role in CRS pathophysiology, as they are higher in patients with CRS than in patients without [25-28]. To date, there is no evidence that T-cells or CAR-T cells are a significant source of IL-6 production [29, 30].

The leading symptom is fever, defined as $\geq 38.0^{\circ} \mathrm{C}$, and is required for a diagnosis of CRS [10]. Other nonspecific symptoms, including malaise, myalgia, fatigue, gastrointestinal complaints (nausea, vomiting, diarrhea), tachycardia, and rash, may also be present $[9,16,17,31]$. The CRS may be self-limiting and can resolve with supportive care alone or may become lifethreatening with capillary leak leading to pulmonary edema, hypotension, multiorgan failure, and circulatory collapse $[9,20]$, see also Table 1 .

\section{Immune effector cell-associated neurotoxicity syndrome (ICANS)}

The ICANS was reported to become manifest in around $40 \%$ of CAR-T cell recipients [32]. The onset of neurotoxicity typically occurs after the start of CRS, and sometimes even after CRS has completely resolved [18]. Typically, ICANS becomes clinically manifest within 4-10 days following CAR-T cell infusion [3, 4, 20].

The mechanisms underlying CAR-T cell-related neurotoxicity are not yet fully understood but disruption of the brain-blood barrier and cerebral edema via cytokine release by CAR-T seem to be key features of ICANS [3, 18]. In up to $95 \%$ of patients, CAR-T cells could be detected in the cerebrospinal fluid (CSF); however, the numbers did not correlate with the severity of ICANS as they could also be found in patients without neurological pathology [18, 33].

Patients with ICANS often develop a characteristic sequence of neurologic symptoms [10, 31], with tremor, dysgraphia, mild expressive aphasia, apraxia and impaired attention in the initial phase. Particularly, expressive aphasia evolving over a period of hours to global aphasia has been reported as a specific symptom [18]. This characteristic finding of an awake patient who is mute and unable to follow commands distinguishes ICANS from other causes of encephalopathy [31]. Furthermore, neurotoxicity can 
Table 1 ASTCT CRS and ICANS consensus grading for adults [10]

\begin{tabular}{|c|c|c|c|c|}
\hline & Grade 1 & Grade 2 & Grade 3 & Grade 4 \\
\hline \multicolumn{5}{|l|}{ CRS parameter } \\
\hline \multirow[t]{2}{*}{ Fever $^{\mathrm{a}}$} & $\geq 38.0$ & $\geq 38.0$ & $\geq 38.0$ & $\geq 38.0$ \\
\hline & & \multicolumn{3}{|c|}{ With } \\
\hline \multirow[t]{2}{*}{ Hypotension } & None & Not requiring vasopressors & $\begin{array}{l}\text { Requiring vasopressors +/- } \\
\text { vasopressin }\end{array}$ & $\begin{array}{l}\text { Requiring multiple vasopres- } \\
\text { sors (excl. vasopressin) }\end{array}$ \\
\hline & & \multicolumn{3}{|c|}{ And/or } \\
\hline Hypoxia & None & $\begin{array}{l}\text { Requiring low-flow nasal } \\
\text { cannula } \\
(\leq 6 \mathrm{~L} / \mathrm{min})\end{array}$ & $\begin{array}{l}\text { Requiring high-flow nasal } \\
\text { cannula ( }>6 \mathrm{~L} / \mathrm{min}) \\
\text { facemask, nonrebreather } \\
\text { mask, or venturi mask }\end{array}$ & $\begin{array}{l}\text { Requiring positive pressure } \\
\text { (e.g. CPAP, BiPAP, and me- } \\
\text { chanical ventilation) }\end{array}$ \\
\hline \multicolumn{5}{|l|}{ Neurotoxicity domain } \\
\hline ICE score ${ }^{b}$ & $7-9$ & $3-6$ & $0-2$ & $\begin{array}{l}0 \\
\text { (patient is unarousable and } \\
\text { unable to perform ICE) }\end{array}$ \\
\hline $\begin{array}{l}\text { Depressed level of conscious- } \\
\text { ness }\end{array}$ & Awakens spontaneously & Awakens to voice & $\begin{array}{l}\text { Awakens only to tactile stimu- } \\
\text { lus }\end{array}$ & $\begin{array}{l}\text { Patient is unarousable or } \\
\text { requires vigorous or repetitive } \\
\text { tactile stimuli to arouse. Stupor } \\
\text { or coma }\end{array}$ \\
\hline Seizure & N/A & $\mathrm{N} / \mathrm{A}$ & $\begin{array}{l}\text { Any clinical seizure, focal or } \\
\text { generalized, that resolves } \\
\text { rapidly or non-convulsive } \\
\text { seizures on EEG that resolve } \\
\text { with intervention }\end{array}$ & $\begin{array}{l}\text { Life-threatening prolonged } \\
\text { seizure ( }>5 \mathrm{~min}) \text {; or repetitive } \\
\text { clinical or electrical seizures } \\
\text { without } \\
\text { return to baseline in between }\end{array}$ \\
\hline Motor findings & N/A & $\mathrm{N} / \mathrm{A}$ & $N / A$ & $\begin{array}{l}\text { Deep focal motor weakness } \\
\text { such as hemiparesis or para- } \\
\text { paresis }\end{array}$ \\
\hline Elevated ICP/cerebral oedema & N/A & $\mathrm{N} / \mathrm{A}$ & $\begin{array}{l}\text { Focal/local edema on } \\
\text { neuroimaging }\end{array}$ & $\begin{array}{l}\text { Diffuse cerebral oedema on } \\
\text { neuroimaging; decerebrate } \\
\text { or decorticate posturing; or } \\
\text { cranial nerve VI } \\
\text { palsy; or papilledema; or Cush- } \\
\text { ing's triad }\end{array}$ \\
\hline \multicolumn{5}{|c|}{$\begin{array}{l}\text { ASTCT American Society for Transplantation and Cellular Therapy, CRS cytokine release syndrome, ICANS immune effector cell-associated neurotoxicity syn- } \\
\text { drome, CPAP Continuous Positive Airway Pressure Therapy, BiPAPBilevel Positive Airway Pressure Therapy } \\
\text { aFever is the sole symptom required for classification as grade } 1 \text {. In patients who have CRS who undergo antipyretic or anticytokine therapy (tocilizumab or } \\
\text { steroids), fever is no longer required to grade subsequent CRS severity, CRS grading is then defined by hypotension and/or hypoxia } \\
\text { b/CE immune effector cell-associated encephalopathy score: } 1 \text { point for each: year, month, name city, hospital, one point for every object correctly identified } \\
\text { (max. } 3 \text { points), follow command, write a standard sentence, and count backwards from } 100 \text { by } 10 \text {. Score of } 10 \text { : no impairment. CRS and ICANS grades are } \\
\text { determined by the most severe event not attributable to any other cause }\end{array}$} \\
\hline
\end{tabular}

proceed to diffuse cerebral edema with subclinical or clinical seizures [10].

For the assessment and grading of CAR-related encephalopathy, the so-called immune effector cell-associated encephalopathy (ICE) score has been developed [10]. The latter score has recently replaced the CARTOX-10, both scores incorporate key elements of the mini-mental state examination and evaluate alterations in speech, orientation, handwriting, and concentration (Table 1; [10]).

\section{Important differential diagnoses}

Due to the similarity of symptoms and the immunosuppressed state of the patient it is crucial to exclude sepsis and treat infections appropriately. In a recent study on outcomes in critically ill CAR $\mathrm{T}$ recipients, sepsis was one of the main reasons for ICU admission [34]. Sepsis-related encephalopathy and meningitis/encephalitis can mimic ICANS. Moreover, severe CRS has been associated with a higher infection risk [35]. The reason for this association is unclear: high cytokine levels, immunosuppressive therapies, aggressive supportive care, and intensive care unit (ICU) management might play a role. Tumor lysis syndrome can usually be distinguished by typical laboratory findings, such as hyperuricemia, hyperkalemia, hypocalcemia, and hyperphosphatemia [36]; however, tumor lysis syndrome and CRS may occur coincidentally [37]. Furthermore, the progression of the underlying malignancy may cause tumor-associated fever and other clinical, metabolic, and imaging abnormalities that resemble those of CRS. CRS is reminiscent of macrophage activation syndrome (MAS) as well as hemophagocytic lymphohistiocytosis (HLH). Both represent syndromes with dysregulated immune response resulting in a severe cytokine storm, hence laboratory findings and the cytokine profile are closely related between MAS/HLH and severe CRS [38]. Thus, MAS/HLH might be regarded as consequence of CRS and CAR-T cells acting as a trigger for subsequent development of HLH/MAS [39]. In addition, fungal 
infections as well as fulminant relapses of the underlying disease might be triggers for HLH/MAS [40], which is why consistent and repeated investigation are important once a diagnosis of $\mathrm{HLH}$ following CAR-T therapy has been established.

Hypersensitivity reactions may appear after CAR $\mathrm{T}$ infusions and typically present with rash and urticaria, fever, dyspnea, hypotension, and gastrointestinal symptoms and eventually cardiorespiratory failure. Considering ICANS, important differential diagnoses are intracranial bleeding (especially when thrombocytopenia is present) or stroke. ICANS can result in epileptic seizures, which have to be identified in an electroencephalogram (EEG), especially when nonconvulsive.

\section{Management of CAR T-cell-related toxicities}

Timely recognition and interdisciplinary management are key components for the management of patients developing CAR T-related toxicities. The CARTOX group recommends a grade-based management approach for CRS and neurologic toxicity [9, 10, 15]. According to these guidelines and management recommendations, lower grade ICANS and CRS can be managed on the ward with supportive and/or pharmacologic therapy. Management of early stages of CRS and ICANS (grade 1-2) includes ruling out infections and other important differential diagnoses. Whilst most of the patients respond well to supportive care including antipyretics and intravenous fluid hydration, early administration of tocilizumab in patients with lower grade CRS may be increasingly considered standard of care. With respect to ICANS, swallowing assessment and aspiration precautions are recommended. Additionally, cerebral imaging (preferably MRI [21]) and EEG should be considered [41]. In the absence of seizures, prophylactic levetiracetam is recommended [9, 21, 42], but the duration and dose have not yet been determined. In general, an early strong collaboration between MET, hematooncologists, neurologists and other organ specialists is crucial. Therefore, at our centr we adapted current CAR T-related toxicity guidelines and developed a concise algorithm to be used by our MET (Fig. 1).

\section{Criteria for ICU admission}

In general, patients with higher $(\geq 3)$ grade of toxicity (see also Table 1) should be managed on the ICU [9, $10,15,16,43]$. Thus, patients requiring one or more organ support or have a reduced level of consciousness fulfil the criteria for ICU admission [10, 16]; however, a recently published survey evaluating ICU management of CAR-T cell-associated toxicities revealed that a majority of ICU admitted patients presented with CRS grade 1-2 (73\%) and ICANS grade 2 (81\%) [44]. In this survey, reasons for admitting lower grade toxicities were concerns for later deterioration, need for further interventions, concerns for evolving noncardiogenic pulmonary edema, or risk for rapid deterioration due to large tumor burden [10]. The CARTTAS trial investigating outcomes in patients treated with CAR-T cells revealed that about $30 \%$ of the patients required admission to ICU, all for CRS, ICANS, or sepsis [34].

\section{Intensive care management}

Supportive management of organ dysfunction or failure follows respective standard intensive care guidelines [11, 31]. The CAR-ICU survey has shown that management practices are very similar amongst participating units [44]. For the fluid management, most units use repetitive fluid bolus of $4 \mathrm{ml} / \mathrm{kg}$ BW, and fluid responsiveness was assessed with noninvasive modes (stroke volume variation, cardiac output, ultrasound guided). Early experience has shown that treating persistent hypotension in CRS with overt fluid management was inferior to early vasopressors use [10]. First line vasopressor in most units is noradrenaline, followed by vasopressin and epinephrine [44]. For patients with respiratory failure, most units perform a noninvasive ventilation trial before intubation [44]. In patients with prolonged severe CRS (persisting for $>72 \mathrm{~h}$ without response to intervention), a cardiac assessment, including cardiac biomarkers (e.g. troponin, NT-proBNP/BNP) or the performance of a echocardiography, is recommended [21]. For patients with neurotoxicity, along with neuroprotective measurements, more invasive intracranial pressure monitoring and enhanced neuroprotective treatment (hypertonic saline, mannitol, pharmacological coma) might be necessary $[9,15,45,46]$. Nonconvulsive and convulsive status epilepticus should be managed with benzodiazepines and additional antiepileptic drugs, preferably levetiracetam, followed by phenobarbital [9]. As sepsis at ICU admission might be an important determinant of mortality in this patient population, particularly when they are neutropenic, screening for infections and commencing broad-band antibiotics has to be considered [34].

\section{Specific therapies}

Corticosteroids are immunosuppressive and are effective in the management of CRS and ICANS [11, $16,47]$. Intravenous corticosteroids are the first-line therapy for patients with ICANS $\geq$ grade 2 [18], while in CRS they are used for second-line in case of refractory symptoms. Recent recommendations even suggested to add steroid in cases of severe CRS not responding to first dose of tocilizumab [21]; however, the evidence for this is not sound and therefore needs to be considered individually In both CRS and ICANS, methylprednisolone $(2 \mathrm{mg} / \mathrm{kg}$ and day) or dexamethasone $(0.5 \mathrm{mg} / \mathrm{kg}$, maximum $10 \mathrm{mg})$ are commonly used steroids. To avoid jeopardizing CAR-T cell func- 


\section{Criteria for ICU Admission}

SBP $<90 \mathrm{mmHg}$ refractory to IV fluid challenge requiring vasopressors $\underline{\mathrm{OR}}$ Hypoxia/respiratory distress with incrasing oxygen requirement ( $\geq 6 \mathrm{~L} \mathrm{O} 2 / \mathrm{min}$ ) or need for ventilatory support $\underline{\mathrm{OR}}$

- $\quad$ ECG changes and/or clinically significant arrhythmias, acute coronary syndrome with positive troponin $\underline{\mathrm{OR}}$

- $\quad$ ICE-Test $\leq 6$ points, signs of raised ICP, $\underline{\text { OR }}$ seizures

- Team concern
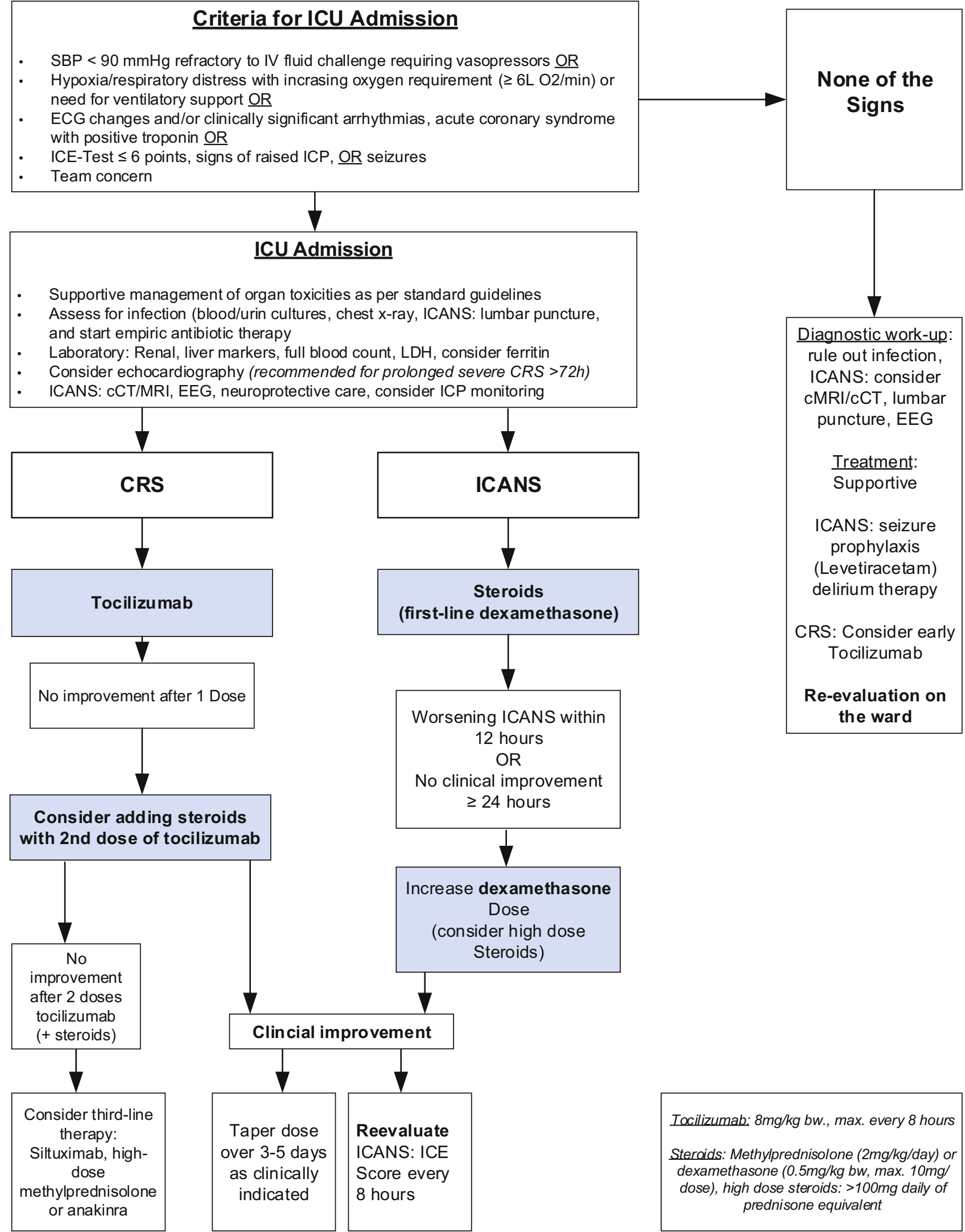

Fig. 1 Medical emergency team (MET) algorithm for the assessment and management of CAR-T related toxicities. Algorithm adapted from Lee et al. [10], Park et al. [12], and Maus et al. [21]. CRS cytokine release syndrome, ICANS immune effector cell-associated neurotoxicity syndrome, ICE immune

effector cell-associated encephalopathy, $C C T$ cerebral computed tomography, $M R I$ magnetic resonance imaging, ICP intracranial pressure, $L D H$ lactate dehydrogenase, EEG electroencephalogram 
tion, the initial recommendation of steroid use was limited to patients with CRS refractory to anti-IL-6 therapy or patients with grade 3-4 CRS toxicities [9]. Today, however, this concern turns out to be unjustified [46, 48-50]. Once CRS symptoms are improving, steroids should be gradually tapered off [21].

Tocilizumab, an IL-6R antagonist, represents the first-line immunosuppressive therapy of CRS [16]. It binds both the soluble and the cell-associated IL-6 receptor. In several studies, tocilizumab has proven to be effective for severe or life-threatening CRS, and usually patients with CRS rapidly respond to tocilizumab-fever and hypotension often resolve within a few hours [51, 52]; however, considerations have been given to use tocilizumab pre-emptively or even as prophylaxis, as blocking IL-6 with tocilizumab neither significantly compromised therapeutic efficacy of CAR-T cells, nor did it negatively affect prognosis of the CAR-T cell recipients [3, 9, 48, 53]. For patients with isolated ICANS, tocilizumab was shown to be ineffective and should only be administered in patients with concurrent CRS [18, 30, 32]. This might be due to the fact that tocilizumab does not cross the blood-brain barrier [16]; however, IL-6 is likely involved in the pathogenesis of CAR Trelated neurotoxicity and levels of IL- 6 have shown to rise transiently following tocilizumab administration, which might lead to an aggravation of neurologic symptoms [16].

Siltuximab is a direct IL-6 antagonist and has similar effects as tocilizumab. Siltuximab might have a favorable outcome in the case of passive diffusion of IL-6 into the CNS [9]; however, a randomized prospective comparison between siltuximab and tocilizumab is still missing [9] and siltuximab has not yet been approved for this indication by US and European drug agencies (FDA and EMA).

For therapy refractory CRS, the addition of third line therapies has been suggested [21]; however, these therapies are currently considered investigational. Whereas IL-6 blockade prevents mainly CRS, the additional IL-1 blockade achieved with the use of anakinra could potentially prevent both CRS and ICANS [30]. A recent report suggested that anakinra could be a potential steroid-sparing strategy for the treatment of CAR T-cell therapy-associated toxicities, mainly ICANS. Several clinical trials investigating its early and/or prophylactic use are ongoing [54].

\section{Conclusion}

In parallel with the introduction of potentially curative CAR-T cell therapies, the spectrum of unique toxicities is growing as well. Tocilizumab is the mainstay pharmacologic therapy for CRS, while corticosteroids should be reserved for neurologic toxicities and CRS not responsive to tocilizumab. An established multidisciplinary collaboration between dedicated hematooncologists, organ specialists and critical care physi- cians is crucial in the management of these patients. Improved knowledge of CAR-T related toxicities, and development of new pharmacological options, especially for prevention and therapy of ICANS, will hopefully further increase safety and practicability of CAR-T cell application in the near future.

Funding Departmental funding only.

Author Contribution All authors contributed to writing the manuscript and approved the final manuscript. ASM and YAQ had the idea for the article. ASM, TP, VUB drafted the manuscript. UN and TP are primarily involved in the patient care. YAQ, UN, CS, and YB critically revised the work.

Funding Open access funding provided by University of Bern

Conflict of interest A.S. Messmer, Y.-A. Que, C. Schankin, Y. Banz, U. Bacher, U. Novak and T. Pabst declare that they have no competing interests.

Open Access This article is licensed under a Creative Commons Attribution 4.0 International License, which permits use, sharing, adaptation, distribution and reproduction in any medium or format, as long as you give appropriate credit to the original author(s) and the source, provide a link to the Creative Commons licence, and indicate if changes were made. The images or other third party material in this article are included in the article's Creative Commons licence, unless indicated otherwise in a credit line to the material. If material is not included in the article's Creative Commons licence and your intended use is not permitted by statutory regulation or exceeds the permitted use, you will need to obtain permission directly from the copyright holder. To view a copy of this licence, visit http://creativecommons.org/licenses/by/4.0/.

\section{References}

1. Demaria O, Cornen S, Daëron M, et al. Harnessing innate immunity in cancer therapy. Nature. 2019;574(7776):45-56.

2. Kochenderfer JN, Rosenberg SA. Treating B-cell cancer with $\mathrm{T}$ cells expressing anti-CD19 chimeric antigen receptors. NatRev Clin Oncol. 2013;10(5):267-76.

3. Neelapu SS, Locke FL, Bartlett NL, et al. Axicabtagene ciloleucel CAR T-cell therapy in refractory large B-cell lymphoma. NEngl J Med. 2017;377(26):2531-44.

4. Schuster SJ, Bishop MR, Tam CS, et al. Tisagenlecleucel in adult relapsed or refractory diffuse large B-cell lymphoma. NEnglJ Med. 2019;380(1):45-56.

5. Wang M, Munoz J, Goy A, et al. KTE-X19 CAR T-cell therapy in relapsed or refractory mantle-cell lymphoma. N Engl J Med. 2020;382(14):1331-42.

6. Maude SL, Laetsch TW, Buechner J, et al. Tisagenlecleucel in children and young adults with B-cell lymphoblastic leukemia. NEnglJ Med. 2018;378(5):439-48.

7. Brudno JN, Kochenderfer JN. Chimeric antigen receptor T-cell therapies for lymphoma. Nat Rev Clin Oncol. 2018;15(1):31-46.

8. Munshi NC, Anderson LD Jr., Shah N, et al. Idecabtagene vicleucel in relapsed and refractory multiple myeloma. NEngl J Med. 2021;384(8):705-16.

9. Neelapu SS, Tummala S, Kebriaei P, et al. Chimeric antigen receptor T-cell therapy-assessment and management of toxicities. Nat RevClin Oncol. 2018;15(1):47-62.

10. Lee DW, Santomasso BD, Locke FL, et al. ASTCT consensus grading for cytokine release syndrome and neurologic 
toxicity associated with immune effector cells. Biol Blood MarrowTransplant. 2019;25(4):625-38.

11. Brudno JN, Kochenderfer JN. Toxicities of chimeric antigen receptor T cells: recognition and management. Blood. 2016;127(26):3321-30.

12. Park JH, Rivière I, Gonen $M$, et al. Long-term follow-up of CD19 CAR therapy in acutelymphoblasticleukemia. NEngl JMed. 2018;378(5):449-59.

13. Tyagarajan S, Spencer T, Smith J. Optimizing CAR-T cell manufacturing processes during pivotal clinical trials. Mol Ther Methods Clin Dev. 2020;16:136-44.

14. MD Anderson Cancer Center. CARTOX app Version 2.3. https://play.google.com/store/apps/details? id=org.mdanderson.cartox\&hl=de_CH\&gl=US; https:// apps.apple.com/ch/app/cartox/id1464005828?l=en.

15. Neelapu SS. Managing the toxicities of CAR T-cell therapy. HematolOncol. 2019;37(S1):48-52.

16. Lee DW, Gardner R, Porter DL, et al. Current concepts in the diagnosis and management of cytokine release syndrome. Blood. 2014;124(2):188-95.

17. Shimabukuro-Vornhagen A, Godel P, Subklewe M, et al. Cytokine release syndrome. J Immunother Cancer. 2018;6(1):56.

18. Santomasso BD, Park JH, Salloum D, et al. Clinical and biological correlates of neurotoxicity associated with CAR T-cell therapy in patients with B-cell acute lymphoblastic leukemia. Cancer Discov. 2018;8(8):958-71.

19. Nastoupil LJ, Jain MD, Feng L, et al. Standard-of-care axicabtagene ciloleucel for relapsed or refractory large B-cell lymphoma: results from the US lymphoma CAR T consortium. JClin Oncol. 2020;38(27):3119-28.

20. Locke FL, Ghobadi A, Jacobson CA, et al. Long-term safety and activity of axicabtagene ciloleucel in refractory large B-cell lymphoma (ZUMA-1): a single-arm, multicentre, phase 1-2 trial. Lancet Oncol. 2019;20(1):31-42.

21. Maus MV, Alexander S, Bishop MR, et al. Society for Immunotherapy of Cancer (SITC) clinical practice guideline on immune effector cell-related adverse events. J Immunother Cancer. 2020;8(2):e1511.

22. Abramson JS, Gordon LI, Palomba ML, et al. Updated safety and long term clinical outcomes in TRANSCEND NHL 001, pivotal trial of lisocabtagene maraleucel (JCAR017) in R/R aggressive NHL. JClin Oncol. 2018;36(15):7505.

23. Godel P, Shimabukuro-Vornhagen A, von Bergwelt-Baildon $\mathrm{M}$. Understanding cytokine release syndrome. Intensive Care Med. 2018;44(3):371-3.

24. Tanaka T, Narazaki M, Kishimoto T. Immunotherapeutic implications of IL-6 blockade for cytokine storm. Immunotherapy. 2016;8(8):959-70.

25. Brentjens RJ, Davila ML, Riviere I, et al. CD19-targeted T cells rapidly induce molecular remissions in adults with chemotherapy-refractory acute lymphoblastic leukemia. SciTransl Med. 2013;5(177):177ra38.

26. Winkler U, Jensen M, Manzke O, et al. Cytokine-release syndrome in patients with B-cell chronic lymphocytic leukemia and high lymphocyte counts after treatment with an anti-CD20 monoclonal antibody (rituximab, IDECC2B8). Blood. 1999;94(7):2217-24.

27. Teachey DT, Rheingold SR, Maude SL, et al. Cytokine release syndrome after blinatumomab treatment related to abnormal macrophage activation and ameliorated with cytokine-directed therapy. Blood. 2013;121(26):5154-7.

28. Hay KA, Hanafi LA, Li D, et al. Kinetics and biomarkers of severe cytokine release syndrome after CD19 chimeric antigen receptor-modified T-cell therapy. Blood. 2017;130(21):2295-306.
29. Singh N, Hofmann TJ, Gershenson Z, et al. Monocyte lineage-derived IL-6 does not affect chimeric antigen receptor T-cell function. Cytotherapy. 2017;19(7):867-80.

30. Norelli M, Camisa B, Barbiera G, et al. Monocyte-derived IL- 1 and IL- 6 are differentially required for cytokine-release syndrome and neurotoxicity due to CAR T cells. Nat Med. 2018;24(6):739-48.

31. Kennedy LB, Salama AKS. A review of cancer immunotherapy toxicity. CACancer J Clin. 2020;70(2):86-104.

32. Gust J, Hay KA, Hanafi LA, et al. Endothelial activation and blood-brain barrier disruption in neurotoxicity after adoptive immunotherapy with CD19 CAR-T cells. Cancer Discov. 2017;7(12):1404-19.

33. Hu Y, Sun J, Wu Z, et al. Predominant cerebral cytokine release syndrome in CD19-directed chimeric antigen receptor-modified T cell therapy. J Hematol Oncol. 2016;9(1):70.

34. Azoulay É, Castro P, Maamar A, et al. Outcomes in patients treated with chimeric antigen receptor T-cell therapy who were admitted to intensive care (CARTTAS): an international, multicentre, observational cohort study. Lancet Haematol. 2021;8(5):e355-e64.

35. Hill JA, Li D, Hay KA, et al. Infectious complications of CD19-targeted chimeric antigen receptor-modified T-cell immunotherapy. Blood. 2018;131(1):121-30.

36. Howard SC, Jones DP, Pui C-H. The tumor lysis syndrome. NEngl J Med. 2011;364(19):1844-54.

37. Howard SC, Trifilio S, Gregory TK, et al. Tumor lysis syndrome in the era of novel and targeted agents in patients with hematologic malignancies: a systematic review. Ann Hematol. 2016;95(4):563-73.

38. Borrega JG, Gödel P, Rüger MA, Onur ÖA, ShimabukuroVornhagen A, Kochanek M, et al. In the eye of the storm: immune-mediated toxicities associated with CAR-T cell therapy. Hemasphere. 2019;3(2):e191.

39. Hashmi H, Bachmeier C, Chavez JC, et al. Haemophagocytic lymphohistiocytosis has variable time to onset following CD19 chimeric antigen receptor $\mathrm{T}$ cell therapy. $\mathrm{Br} \mathrm{J}$ Haematol. 2019;187(2):e35-e8.

40. Eloseily EM, Cron RQ. Macrophage activation syndrome. Microbiome Rheum Dis Infect. 2018; https://doi.org/10. 1007/978-3-319-79026-8 14.

41. Rubin DB, Danish HH, Ali AB, et al. Neurological toxicities associated with chimeric antigen receptor T-cell therapy. Brain. 2019;142(5):1334-48.

42. Perrinjaquet C, Desbaillets N, Hottinger AF. Neurotoxicity associated with cancer immunotherapy: immune checkpoint inhibitors and chimeric antigen receptor T-cell therapy. Curr Opin Neurol. 2019;32(3):500-10.

43. GutierrezC,McEvoyC, Munshi L, etal. Critical caremanagement of toxicities associated with targeted agents and immunotherapiesfor cancer. CritCareMed. 2020;48(1):10-21.

44. Gutierrez C, Brown ART, Herr MM, et al. The chimeric antigen receptor-intensive care unit (CAR-ICU) initiative: surveying intensive care unit practices in the management of CAR T-cell associated toxicities. J Crit Care. 2020;58:58-64.

45. Zytoun TM, Mahrous AA, Megahed MM, et al. Colloid versus crystalloid in septic neutropenic patients using serum neutrophil gelatinase-associated lipocalin (NGAL) as an early marker of acute renal failure. Intensive Care Med. 2014;40(1):S111.

46. Karschnia P, Jordan JT, Forst DA, et al. Clinical presentation, management, and biomarkers of neurotoxicity after adoptive immunotherapy with CAR T cells. Blood. 2019;133(20):2212-21.

47. Maude SL, Barrett D, Teachey DT, et al. Managing cytokine release syndrome associated with novel $\mathrm{T}$ cell-engaging therapies. Cancer J. 2014;20(2):119-22. 
48. Gardner RA, Ceppi F, Rivers J, et al. Preemptive mitigation of CD19 CAR T-cell cytokine release syndrome without attenuation of antileukemic efficacy. Blood. 2019;134(24):2149-58.

49. Shah BD, Bishop MR, Oluwole OO, et al. End of phase I results ofZUMA-3, a phase 1/2 study of KTE-X19, anti-CD19 chimeric antigen receptor (CAR) T cell therapy, in adult patients (pts) with relapsed/refractory (R/R) acute lymphoblasticleukemia (ALL). JClin Oncol. 2019;37(15):7006.

50. Liu S, Deng B, Yin Z, et al. Corticosteroids do not influence the efficacy and kinetics of CAR-T cells for B-cell acute lymphoblasticleukemia. Blood Cancer J.2020;10(2):15.

51. Grupp SA, Kalos M, Barrett D, et al. Chimeric antigen receptor-modified $\mathrm{T}$ cells for acute lymphoid leukemia. NEngl J Med. 2013;368(16):1509-18.
52. Bonifant CL, Jackson HJ, Brentjens RJ, et al. Toxicity and management in CAR T-cell therapy. Mol Ther Oncolytics. 2016;3:16011.

53. Schuster SJ, Maziarz RT, Rusch ES, et al. Grading and management of cytokine release syndrome in patients treated with tisagenlecleucel in the JULIET trial. Blood Adv. 2020;4(7):1432-9.

54. Strati P, Ahmed S, Kebriaei P, et al. Clinical efficacy of anakinra to mitigate CAR T-cell therapy-associated toxicity inlarge B-cell lymphoma. Blood Adv. 2020;4(13):3123-7.

Publisher's Note Springer Nature remains neutral with regard to jurisdictional claims in published maps and institutional affiliations. 